\title{
VERKANNTE WeiblichKeit? - Fulvia in DER ERFÜLLUNG SOZIALER ROLLEN EINER MATRONA ROMANA
}

\author{
SANDRA Kaden \\ Universität Potsdam
}

ZuSAMMENFASSUNG: Fulvia nahm unter den Frauen der späten Republik eine herausgehobene Position ein. Diese konstituierte sich durch ihren familiären Status und die Tatsache, dass sie nacheinander mit drei bedeutenden Politikern - P. Clodius Pulcher, C. Scribonius Curio, M. Antonius - verheiratet war. Schon Zeitgenossen lasteten ihr ein negatives, sie zum Mannweib stilisierendes Charakterbild an. Erst die moderne Forschung hat allmählich zur Aufweichung dieses Zerrbildes beigetragen, dabei aber Fulvias weibliche Rollenentsprechung weiterhin ausgeblendet. Eine Neubewertung zeigt allerdings, dass Fulvia dem Ideal einer matrona Romana durchaus zu entsprechen vermochte. Als filia familia war sie in der Lage, eine achtbare Herkunft, ein stattliches Vermögen und eine adäquate Erziehung vorzuweisen. Ebenso galt sie als ehrbare mater familias, da sie fünf Kinder gebar, diese erzog und beschützte sowie ihren Ehemännern als kompromisslose Gefährtin zur Seite stand. Schließlich muss auch Fulvias rigoroses Auftreten im Perusinischen Krieg im Jahr 41/40 v. Chr. als Demonstration bedingungsloser pietas gewertet werden, auch wenn sie damit die Grenzen des traditionell Weiblichen endgültig überschritten hatte.

Schlagworte: späte Römische Republik, Fulvia, römische Rollenkonstruktion, matrona Romana, pietas.

ABSTRACT: Fulvia held an outstanding position among the women of the late Republic. This position was based partially on her family status and partially on her successive marriages with three important politicians: P. Clodius Pulcher, C. Scribonius Curio and M. Antonius. Even her contemporaries accused her of having a negative character image, 
stylizing her as a mannish woman. Only recently modern researchers have begun to weaken this distorted picture. Yet, they continued to completely ignore Fulvia as a female role model. A revaluation shows, however, that Fulvia could indeed meet the ideal of a matrona Romana. As filia familia she was able to produce a respectable family background, considerable assets and an adequate education. Furthermore, since she gave birth to five children, raised and protected them, as well as uncompromisingly supported her husbands, she was also considered a respectable mater familias. Ultimately, her rigorous stance during the Perusian War of 41/40 B.C. has to be valued as a demonstration of unconditional pietas, even though by doing so she violated the boundaries of traditional womanhood once and for all.

Keywords: late Roman Republic, Fulvia, construction of Roman gender roles, matrona Romana, pietas.

Fulvia, die Gemahlin des Marcus Antonius, ein Weib mit allen Lastern des verworfensten Charakters, herrschsüchtig, grausam, zügellos und blutgierig, war die Witwe des Clodius, des bekannten Feindes Cicero's, als sich Antonius mit ihr vermählte. Während der Herrschaft der Triumvirn, Octavianus, Antonius und Crassus [sic! = Lepidus, S.K.], übte sie die schrecklichsten Gräuel aus, und füllte die Proscriptionslisten mit den Opfern ihrer Rache an. Unter ihnen war auch Cicero; selbst noch das abgeschlagene Haupt des großen Mannes schändete sie durch Verstümmelungen. Während ihr Gemahl in Aegypten abwesend, in den Armen der Cleopatra sie vergaß, erregte sie eine Empörung gegen ihn, an deren Spitze Antonius's Bruder, Lucius, trat. Octavian kam noch früh genug, sein Heer diesem Feinde entgegen zu führen. Fulvia begab sich nach Griechenland und starb daselbst zu Sicyone an einer Krankheit, die ihr die Heftigkeit ihres Zornes und die Eifersucht auf Antonius Verhältniß mit der ägyptischen Königin zugezogen hatte, 40 vor Christus. ${ }^{1}$

Tm Damen Conversations Lexikon aus dem Jahr 1835 werden Fulvia Eigenschaften zur Last gelegt, die dem Bild vom sittlich einwandfreien Benehmen einer römischen Matrone zutiefst widersprechen. So wird sie dem Leser als eine befehlshaberische, ehrsüchtige und zügellos grausame Frau suggeriert, die aus Eifersucht sogar einen Krieg entfacht, nur um ihren 
Ehemann, den Triumvirn Marcus Antonius, den Fängen der ägyptischen Königin Kleopatra VII. zu entreißen und ihn wieder nach Rom zurückzuführen. Den Ursprung jener diskreditierenden Charakterdarstellung bilden die von den antiken Autoren verwendeten Negativtopoi, durch die Fulvia zum «Mannweib» abgestempelt wird. ${ }^{2}$ Das Zerrbild, das durch diese antike Stilisierung konstruiert und von den Historikern des 19. Jahrhunderts nahezu unverändert übernommen wurde, wirkte bis weit in das 20. Jahrhundert hinein. ${ }^{3}$ Zwar bekunden die jüngeren Studien eine modifizierte Sichtweise auf Fulvia, indem sie ihr politisch außergewöhnliches Handeln posthum als richtungsweisend für das selbstbewusste Auftreten und Agieren späterer Kaiserfrauen würdigen. ${ }^{4}$ Dennoch liegt auch dieser Wertschätzung nach wie vor Fulvias nonkonformes Verhalten zu Grunde, das sie bereits zu ihren Lebzeiten ihrem Weiblichkeitscharakter fast vollständig enthob und stattdessen einem usurpierten männlichen Habitus zugeführt haben soll. Weiterhin unberücksichtigt blieb hingegen Fulvias weibliche Rollenentsprechung, mit der sie die an eine matrona Romana gestellten gesellschaftlichen Grundvoraussetzungen durchaus zu erfüllen vermochte. ${ }^{5}$

Diesem Desiderat soll mit der nachfolgenden Analyse abgeholfen werden. Ziel ist, statt wiederholter Betonung des transgressionalen Aspekts von Fulvias Handeln die Suche nach Anhaltspunkten, die ein rollenkonformes Verhalten bekunden und so zu einer multiperspektiven Neubewertung von Fulvias Persönlichkeit beitragen. Zu diesem Zweck erfolgt zunächst ein allgemeiner Überblick zur Stellung der Frau in der späten Republik, der Fulvia innerhalb ihres historischen Umfeldes verortet. Daran anknüpfend werden die an eine römische Frau herangetragenen Aufgaben sowie die ihnen diesbezüglich zugebilligten Aktionsräume im Kontext des geltenden spätrepublikanischen

2. Die zeitgenössische Hauptquelle zu Fulvia stellen die von M. Tullius Cicero verfassten Philippicae dar, in denen er Marcus Antonius scharf angreift und ihn zur größten Bedrohung der libera res publica deklariert. Über die Herabsetzung des Antonius hinaus führt der Autor in seiner Argumentation auch verschiedene negative Topoi gegen Fulvia vor, die den verwerflichen Charakter ihres Ehegatten nochmals unterstreichen sollen. Neben ihrer ehelichen Untreue und niedrigen Abstammung sind es insbesondere die ihr immanente Grausamkeit und Skrupellosigkeit, die Cicero zu diesem Zweck an ihr hervorzuheben sucht. Noch Jahrhunderte später übernahmen Historiker wie Plutarch, Appian und Cassius Dio kritiklos dieses negative Urteil bzw. verstärkten es sogar. Neben den genannten Autoren existieren weitere Schriftzeugnisse über Fulvia, deren Urheber vorrangig der frühen Kaiserzeit entstammten und ihren Erzählstil ganz im Sinne einer geschönten augusteischen Geschichtsbetrachtung gestalteten. In den meist episodenhaften Erwähnungen Fulvias thematisieren sie vorrangig zwei Aspekte, an denen sie zugleich auch Anstoß nehmen: ihre militärische Aktivität (Velleius Paterculus, Florus, Valerius Maximus) sowie ihre moralische Verwerflichkeit (Sueton, Martial).

3. So bezeichnet noch Kornemann, Römische Geschichte, 95, Fulvia als «ein Mannweib übelster Sorte».

4. Exemplarisch etwa bei KRECK, Untersuchungen, 212; BAUMAN, Women and Politics, 89; BLEICKEN, Augustus, 194; Christ, Geschichte der römischen Kaiserzeit, 66, 68. Den Stand der Forschung mit entsprechenden Literaturverweisen fasst erstmals FisCHER, Fulvia und Octavia, 2-4, zusammen.

5. Eine Ausnahme bildet Hesberg-Tonn, Coniunx Carissima, 83, die zumindest zu bedenken gibt, «dass Fulvia im Grunde doch gewisse gesellschaftliche Grundvorstellungen erfüllt. So ist sie reich und vornehmer Abkunft. Sie hat fünf Kinder geboren. Grundsätzlich handelt sie während der Abwesenheit des Ehemannes in seinem Interesse und ihre Ehen zeigen, dass sie durchaus in der Lage ist, als liebende Ehefrau und Mutter zu fühlen.» 
Wertekanons kurz umrissen. Auf Grundlage der auf diese Weise definierten Kriterien, welche die ideale Weiblichkeit in Rom konstituierten, sollen schließlich die Handlungsmuster Fulvias analysiert werden, die sie in ihrer Position als filia familiae und mater familias zeigen und so als matrona Romana ausweisen.

\section{EIN (Frauen-)Leben INNERHALb DER KRISENZEIT DER SPÄTEN RÖMISCHEN REPUBLIK}

Mit ihrer Geburt um das Jahr 75 v. Chr. ${ }^{6}$ wurde Fulvia in die von Wirren und Katastrophen gekennzeichneten letzten Jahrzehnte der späten Republik hineingeboren. ${ }^{7}$ In ihren annähernd 35 Lebensjahren war sie nacheinander mit drei einflussreichen Politikern dieser Zeit verheiratet: in erster Ehe mit P. Clodius Pulcher, dem berühmt-berüchtigten Volkstribun aus dem Jahr 58, in zweiter Ehe mit C. Scribonius Curio, Volkstribun des Jahres 50 und Caesars Legat im Afrikanischen Krieg, und schließlich mit Marcus Antonius, dem bedeutenden Triumvir und späteren Unterlegenen im Machtkampf mit Octavian. Bereits durch ihre familiäre Herkunft, vornehmlich aber durch den staatspolitischen Einfluss ihrer Ehegatten nahm Fulvia lebhaft an den Geschehnissen rund um den innenpolitischen Zerfallsprozess der römischen Republik teil. Wie andere Frauen der Oberschicht stand sie damit zeitlebens im Spannungsfeld der Machtinteressen einzelner politischer Akteure, die aufgrund ihrer exponierten Stellung die Geschicke des Staates lenkten und auf diese Weise maßgeblich zum schicksalsträchtigen Untergang der res publica beitrugen. ${ }^{8}$

Gleichsam ermöglichten die mit Beginn der Römisch-Karthagischen Kriege (264-146) sich verändernden gesellschaftspolitischen Rahmenbedingungen im Bereich des Ehe-, Vormundschafts- und Erbrechts einigen römischen Aristokratinnen - darunter Fulvia - einen erweiterten Gestaltungsspielraum,

6. Sofern nicht anders angegeben, beziehen sich alle folgenden Jahresangaben auf das vorchristliche Jahrhundert. Zu den Problemen einer exakten Datierung von Fulvias Geburt vgl. Fischer, Fulvia und Octavia, $7 \mathrm{f}$

7. Zur Krise der späten Republik mit ausführlichen bibliographischen Hinweisen siehe CHRIST, Krise und Untergang, passim.

8. Vermehrt traten am Ausgang der Römischen Republik und insbesondere nach den Iden des März 44 einzelne Frauen der Oberschicht in den Fokus der Öffentlichkeit, indem sie offenbar zunehmend als wesentliche Machtfaktoren mit Einfluss auf zentrale politische Ereignisse wahrgenommen wurden. Ganz bewusst bezogen die Männer die sie umgebenden Frauen nun als strategisches Moment in ihre rivalisierenden Auseinandersetzungen um die Macht mit ein. So fungierten sie einerseits durch arrangierte Eheschließungen als Unterpfand politischer Bündnisse; andererseits erwies sich ihre Verunglimpfung als opportunes Instrumentarium, den Gegner gezielt herabzusetzen. Einen Höhepunkt derartiger Diffamierungskampagnen für die Zeit des «Zweiten Triumvirats» konstatiert CHRIST, Frauen der Triumvirn, 101. Zur aristokratischen Ehe als politische Allianz siehe Kunst, Eheallianzen, passim, bes. 33f., 41. Weitere, für die Krisenzeit der späten Republik charakteristische Frauenpersönlichkeiten bei Dettenhofer, Aristokratinnen, passim; Hillard, On the Stage, passim. 
der sie nicht nur befähigte, autonom über ihre Person sowie ihr Eigentum zu verfügen, sondern auch eigenen Einfluss auf die politischen Entwicklungen des spätrepublikanischen Staates geltend zu machen. ${ }^{9}$ Hinzu traten demographische Veränderungen, die sich aus dem anhaltenden Kriegszustand seit 264 ergaben. So führten die Kriegshandlungen zu einem hohen Verlust an römischen Männern, ein Zustand, von dem fast jede Frau in Rom betroffen war. Die weiblichen Familienangehörigen sahen sich angesichts dieser Notsituation gezwungen, in männlicher Vertreterfunktion zu agieren und damit zuvor einzig den Männern vorbehaltene Handlungsfelder zu übernehmen. Um das entstandene Vakuum adäquat auszufüllen, hatten sie dafür Sorge zu tragen, die Verpflichtungs- und Abhängigkeitsbeziehungen im Rahmen von amicitia und clientela in Eigenverantwortung $\mathrm{zu}$ pflegen und aufrechtzuerhalten. Sukzessiv erschlossen sich die Römerinnen auf diese Weise Aufgabenbereiche und Betätigungsfelder, die ihren Aktionsradius wesentlich erweiterten, über die tradierte Weitergabe an nachfolgende Generationen festigten und damit alltagstauglich und akzeptanzfähig machten. Auch Fulvia dürfte als Kind jener Zeit entsprechende Erfahrungswerte gesammelt haben. ${ }^{10}$

\section{DAS IDEAL VON WeIBlichKeIt IM KONTEXT RÖMISCHER Rollenerwartung zum ENDE Der Republik.}

In der späten Republik hatte sich ein Idealtypus der römischen Matrone der Oberschicht herausgebildet, der sich aus der adäquaten Rollenentsprechung ihres Ehegattinnen- und Mutterstatus und den damit an sie gestellten Anforderungen konstituierte, die im unmittelbaren Zusammenhang mit der Lebensordnung des Hauses und seinem Bild in der Öffentlichkeit standen. ${ }^{11}$

Bereits die Erziehung der jungen Aristokratin zielte ganz darauf ab, sie auf ihr künftiges Dasein als Ehefrau und Mutter umfassend vorzubereiten. Neben der Unterweisung in den erforderlichen Fertigkeiten der Haushaltsführung,

9. Im Wesentlichen sind es zwei Entwicklungstendenzen innerhalb des privat-rechtlichen Bereiches, die sich nachhaltig auf die Stellung der römischen Frau auszuwirken begannen: Zum einen die allmähliche Durchsetzung der manus-freien Ehe, durch welche die Frau bei Tod des Vaters einem sui iuris-Status verfiel. Als Person «eigenen Rechts» war es ihr nun möglich, losgelöst von ihrem Ehemann, auf der Grundlage ihres ererbten Familienvermögens finanzielle Unabhängigkeit und damit ökonomische Selbständigkeit zu entfalten. Zusammenfallend mit der zum anderen sichtbaren Zurückbildung der tutela mulierum, welche die römische Frau zeitlebens unter Aufsicht eines männlichen Tutors stellte, wurde eine weibliche Vermögens- und Geschäftsfähigkeit bewirkt, die durch den zuletzt nur noch rein formalen Charakter der Frauentutel keine wesentlichen Einschränkungen mehr erfuhr. Zum Rahmen römischer Gesetzgebung im Bereich des Ehe-, Vormundschafts- und Erbrechts vgl. КRECK, Untersuchungen, 7-32; HesberG-TonN, Coniunx Carissima, 14-60; PoMEroy, Frauenleben, 229-250.

10. Vgl. Culham, Women, 150-155; Dettenhofer, Aristokratinnen, $789 f$.

11. Wie schon in der römischen Frühzeit bildete auch zum Ende der Republik der häuslich-private Bereich den legitimen Handlungsrahmen für die Frau, in dessen Grenzen sie ihren Beschäftigungen nachkam, vgl. ERMETe, Terentia und Tullia, 86f. 
wozu insbesondere das Spinnen und die Verarbeitung von Wolle ${ }^{12}$ sowie die Koordination und Überwachung der hauseigenen Sklaven zählten, ${ }^{13}$ erwarben die Mädchen elementare Kenntnisse im Rechnen, Lesen und Schreiben, in der griechischen Sprache sowie der lateinischen und griechischen Dichtung, auch wurden sie in Musik und im Tanz ausgebildet. ${ }^{14}$ Auf diese Weise sollte gewährleistet werden, dass die Töchter der führenden Häuser sich möglichst frühzeitig mit der ihnen zugewiesenen Lebenswelt arrangierten. Ferner mussten sie den im späteren Eheleben gestellten Erwartungen entsprechen, durch Geselligkeit, Gastfreundschaft, Konversationsfähigkeit und weitere unterhaltende Begabungen maßgeblich zur Achtung ihres Ehegatten in der Öffentlichkeit beizutragen. ${ }^{15}$ Neben diesen anerzogenen Qualitäten waren es außerdem eine achtenswerte Abstammung (nobilitas) und ein ansehnliches Vermögen (opes), welche einen vortrefflichen familiären Status dokumentierten und die junge Aristokratin für die Heirat attraktiv machten.

In der Ehe bestand für die Frau die vordringlichste Aufgabe in der Geburt legitimer Nachkommen. Als wichtigste weibliche Eigenschaft erwies sich somit die fertilitas, da nur über sie die Familienkontinuität - und zwar über die Zeugung von Söhnen - und damit gleichsam der Fortbestand der res publica durch eine ausreichende Reproduktion abgesichert werden konnten. ${ }^{16}$ Unter dieser Maßgabe wurden Wiederverheiratungen zum Ende der Republik hin als legitim angesehen, womit sogar das vormalige Ideal der univira und die ihr immanenten Verhaltensweisen dieser Intention untergeordnet wurden. ${ }^{17}$ Insbesondere die im Sinne der Reinhaltung der Familie und der

12. Bis in die augusteische Zeit galt das Spinnen und Weben als die Hauptaufgabe der Römerin. So erwähnt Sueton (Aug. 64,2; 73,1), dass noch die weiblichen Verwandten des Augustus in der Wollarbeit unterrichtet wurden. Schon der Webstuhl selbst galt als Symbol des fraulichen Fleißes und dokumentierte die geschäftige und effiziente Ökonomie des Hauses, weshalb er ostentativ für jeden Besucher sichtbar im Atrium positioniert wurde, vgl. WALlaCe-HAdRILl, Roman House, 109; Kunst, Frauenzimmer, $112 \mathrm{f}$.

13. Durch den im Zuge der römischen Expansion erlangten Wohlstand einiger Familien beschränkte sich der Tätigkeitsbereich der Aristokratinnen in der hohen und späten Republik nunmehr vornehmlich auf das Anleiten und die Beaufsichtigung der Sklaven, die an ihrer statt deren frühere Pflichten übernahmen. Zu den in der Agrargesellschaft der Frühzeit Roms vorherrschenden Aufgaben einer Frau siehe DEISSMANN, Aufgaben, 506-514.

14. Grundlegend zur Erziehung von aristokratischen Töchtern vgl. HeMELRIJK, Matrona Docta, 17-96.

15. Epigraphische Überreste aus der Republik bezeugen die Wertschätzung, die Frauen als Gesellschafterin und Unterhalterin des Mannes entgegen gebracht wurde, vgl. HeSBERG-TonN, Coniunx Carissima, 113, 123. Hemelrijk, Matrona Docta, 79-84, verweist indes auf die Vorurteile, mit denen solche Frauen ebenfalls konfrontiert waren und macht so auf den Gegensatz aufmerksam, der zwischen Ideal und Wirklichkeit augenscheinlich vorherrschte.

16. Zur Ehe als Zweckgemeinschaft im Dienste der Kinderzeugung vgl. DeIssmann, Aufgaben, 505f., 517; Pomeroy, Frauenleben, 253. Als Scheidungsursache wurde demnach oftmals die Kinderlosigkeit angeführt, die stets die Frau zu verschulden hatte. So war z.B. die Ehe von Sempronia, der Tochter des Tiberius Gracchus, vor allem aufgrund ihrer Kinderlosigkeit wohl eine unglückliche, App. civ. 1,20,83. Der gleiche Grund bewog schließlich auch «Turia» (die Authentizität ihres richtigen Namens bleibt ungeklärt) ihrem Mann nach dreiundvierzig kinderlosen Ehejahren die Scheidung anzubieten, der sich diesem Angebot entrüstet verwehrte und damit sogar das Aussterben seiner Familie in Kauf nahm. Allgemein zur Laudatio «Turiae» vgl. Hesberg-Tonn, Coniunx Carissima, 218-237, zum angegebenen Sachverhalt vgl. $225 \mathrm{f}$.

17. Gleichwohl blieb die Verherrlichung der univirae, der Frauen, die ihr ganzes Leben einem einzigen Ehegatten auch über dessen Tod hin treu ergeben blieben und eine Neuheirat ablehnten, als Symbolfiguren des mos maiorum bis in die Zeit des Principats bestehen. Dazu Pomeroy, Frauenleben, $246 f$. 
Nachkommenschaft geforderten Tugenden der Schamhaftigkeit (pudicitia) und der moralischen Keuschheit (castitas) erfuhren vor diesem Hintergrund einen erweiterten Ausdeutungsrahmen, indem sie jetzt auch den wiederverheirateten Frauen zugeschrieben wurden. ${ }^{18}$

Daneben war die Ehefrau ihrem Ehegatten durch die handlungsbestimmenden Tugenden, pietas und fides, fest verbunden. Als kompromisslose Gefährtin stand sie dem Ehepartner in allen Lebenslagen mit bedingungsloser Loyalität und Treue zur Seite. Insbesondere in der Krisenzeit der späten Republik gewann diese Haltung mehr als in den Jahrzehnten zuvor maßgeblich an politischer Brisanz. Bedingt durch das oftmals lange Fernbleiben der Ehemänner sah sich die in Rom zurückgebliebene Ehefrau nun zunehmend in der Pflicht, aktiv für das Wohl und das Überleben der Familie einzutreten. Neben der Übernahme der Vermögensverwaltung und der sittlichen wie moralischen Erziehung der Kinder beinhaltete ein solches Engagement sowohl die intensive Wahrnehmung der familiären gesellschaftlichen Kontakte und das Knüpfen neuer Verbindungen als auch das Durchführen von Gnadenersuchen bei Politikern als Bittstellerin. Die Dringlichkeit dieses konsequenten Eintretens für die Interessen des abwesenden Gatten zeigt sich daran, dass der Ehemann für diese Zeit nicht nur den temporären Eintritt seiner Frau in die politische Sphäre tolerierte, sondern ein derartiges Agieren sogar voraussetzte und nachhaltig unterstützte. Die Duldung dieser femininen Grenzüberschreitung war allerdings nur solange von Dauer, wie die entsprechende Notlage es erforderlich machte. Nach Rückkehr des Hausherrn wurde von der vorbildlichen Matrone erwartet, dass sie sich anstandslos wieder in den ihr angestammten häuslichen Zuständigkeitsbereich zurückzog, wo sie als Leiterin des Hauswesens ihre häusliche Kompetenz durch Tugenden wie Fleiß und Sparsamkeit unter Beweis stellte und dem Ehegatten mit dem gewohnten Gehorsam (obsequium) begegnete. ${ }^{19}$

18. Vgl. Deissmann, Aufgaben, 515, 550f. Gemeinhin gelten für die Römer die mythischen Frauengestalten Verginia und Lucretia als Inbegriff von pudicitia. Zu Verginia vgl. KowalewsKI, Frauengestalten, 142-175. Ausführlich zum so genannten Lucretiamotiv mit entsprechenden Quellenbelegen PRESCENDI, Weiblichkeitsideale, 217-227; KowalewsKi, Frauengestalten, 107-129. Auf einen allgemeinen Wertewandel verweist ERmete, Terentia und Tullia, 86-90.

19. An dieser Stelle sei nochmals auf das Beispiel Turias (vgl. Anm. 16) verwiesen, die in zwei konkreten Situationen in Erfüllung ihrer pietas gegenüber Eltern und Gatten den häuslichen Handlungsbereich verlässt: Nach der Ermordung ihrer Eltern betreibt sie zunächst erfolgreich die Verfolgung und Bestrafung der Schuldigen und erwirkt darüber hinaus noch die Verteidigung des väterlichen Testaments gegenüber Außenstehenden. Ein weiteres Mal übertritt sie während der Proskriptionen im Jahr 43 den ihr zugebilligten weiblichen Aktionsbereich, indem sie sich aktiv (und erneut siegreich!) für die Begnadigung ihres Ehemannes einsetzt. Die positive Bewertung von Turias Verhalten durch ihren Ehegatten erklärt sich vor dem Hintergrund, dass ihre Aktivität in dem Moment erlischt, als keine weitere Gefahrensituation mehr besteht; augenblicklich zieht sie sich daraufhin bereitwillig in ihre häusliche Sphäre zurück. Die entsprechenden Textstellen werden eingehend analysiert bei Hesberg-Tonn, Coniunx Carissima, 227-235. 


\section{Fulvia in DeR ERfüllung SOZIALER Rollen EINER Matrona Romana}

III.1. Fulvia als filia familiae.

a) nobilitas und opes: Abstammung und Familienverhältnisse

Fulvia verfügte aufgrund ihrer Herkunft und den daran geknüpften Besitzverhältnissen über einen achtbaren familiären Status innerhalb der römischen Nobilität. Sie stammte väterlicher- wie mütterlicherseits von zwei altehrwürdigen plebeischen gentes ab, die sich in der Vergangenheit um die Römische Republik verdient gemacht hatten: der Fulvier und der Sempronier. Die sinkende Bedeutung beider Familienzweige im ausgehenden zweiten vorchristlichen Jahrhundert nahm Cicero als willkommenen Anlass, in seiner dritten Philippischen Rede darüber zu berichten. Spöttisch bezeichnet er Fulvia darin als

Tochter eines gewissen Bambalio, einer ausgemachten Null, eines Zipfels ohnegleichen, dem die schwere Zunge und der unbewegliche Geist den verächtlichen Beinamen eingebracht haben. «Doch ihr Großvater ist von Adel.» Du [Antonius, S.K.] meinst gewiss den bekannten Tuditanus: er hatte die Gewohnheit, in der Tracht eines tragischen Schauspielers von der Rednertribüne herab Geld unters Volk zu werfen. Ich wünschte, er hätte diese Geringschätzung von Besitz auf seine Nachkommen vererbt. Da habt ihr ein ruhmreiches Adelsgeschlecht! ${ }^{20}$

Die abfälligen Bemerkungen sowohl zu M. Fulvius (Bambalio), Fulvias Vater, der aufgrund eines Sprachfehlers die Redekunst nicht beherrschte und politisch eher unauffällig gewesen war, als auch zu Sempronius Tuditanus, Fulvias Großvater mütterlicherseits, dem Cicero Verschwendungssucht ${ }^{21}$ und Geisteskrankheit vorwirft, ${ }^{22}$ unterliegen einer klaren Programmatik. Dieser folgend bestand Ciceros vornehmliches Ziel darin, unter Hinweis auf Fulvias augenscheinlich gering geschätzte Verwandtschaft, in erster Linie seinen politischen Widersacher Antonius zu diskreditieren, der durch die Heirat mit Fulvia auch das Andenken an deren Familienangehörige in die memoria seiner eigenen Verwandtschaft übernommen hatte. ${ }^{23}$

20. Cic. Phil 3,16: tuae coniugis, [...] Bambalio quidam pater, homo nullo numero. nihil illo contemptius, qui propter haesitantiam linguae stuporemque cordis cognomen ex contumelia traxerat. «at avus nobilis.» Tuditanus nempe ille, qui cum palla et cothurnis nummos populo de rostris spargere solebat. vellem hanc contemptionem pecuniae suis reliquisset! habetis nobilitatem generis gloriosam.

21. Vornehmlich spielt Cicero damit auf Fulvias Habgier an; ein Sujet, das er wiederholt gegen sie zur Sprache bringt, Cic. Phil. 2,95.113; 3,10; 5,11; 6,4; 13,18.

22. Weder für M. Fulvius noch für Sempronius Tuditanus ist eine Ämterlaufbahn überliefert. $\mathrm{Zu}$ Letzterem Val. Max. 7,8,1, dessen Schriften allerdings stark von der ciceronischen Überlieferung vereinnahmt sind, vgl. Fischer, Fulvia und Octavia, 11, Anm. 24.

23. Insbesondere der Aspekt des schwindenden Einflusses von Fulvias väterlichem Familiengeschlecht im ersten vorchristlichen Jahrhundert hat in der Forschung teilweise zu der Ansicht geführt, Fulvias 
Jeweils unerwähnt lässt Cicero hingegen die Verdienste früherer Vertreter beider gentes. So erlangten nachweislich Mitglieder der Sempronii Tuditani im dritten, aber auch noch im zweiten vorchristlichen Jahrhundert große politische Bedeutung. ${ }^{24}$ Ebenso zählten die Fulvier in der Vergangenheit zum angesehenen Kreis der plebeischen Nobilität, ${ }^{25}$ wie Cicero selbst in einer Rede aus dem Jahr 53 anmerkt. Darin zeichnet er die Fulvier als ein in Tusculum ansässiges Familiengeschlecht aus, das ansehnliche Magistrate, darunter sogar viele Consuln, hervorgebracht habe. ${ }^{26}$

Neben ihrer Familienabstammung konstituierte sich Fulvias Status auch aus einem stattlichen Vermögen, welches ihr durch den Nachlass des Großvaters mütterlicherseits als letzte Vertreterin ihrer gens zur Verfügung stand. Wiederum ist es Cicero, der diesen Aspekt entsprechend zu kommentieren weiß. Nicht ohne sarkastischen Unterton verweist er auf Fulvias einzigen Vorzug, den man ihr als Ehegattin von Antonius zugute halten müsse. Nach ihm sei sie «eine gute Frau - jedenfalls eine reiche». ${ }^{27}$

\section{b) matrona docta: Erziehung und Ausbildung.}

Fulvias Aufwachsen in einem hohen plebeischen Aristokratenhaus wird ihr eine adäquate Erziehung und Ausbildung ermöglicht haben. Jedenfalls legen bestimmte Anhaltspunkte in der Überlieferung nahe, dass bei Fulvia über die Elementarbildung hinaus von weitreichenden hauswirtschaftlichen

Herkunft müsse als weniger bedeutend eingestuft werden, vgl. exemplarisch FörTsCH, Die politische Rolle der Frau, 108; Вавсоск, The early career, 3f.; Ermete, Terentia und Tullia, 79, bes. Anm. 351. Dem widerspricht, dass sich die römische Gesellschaft vor allem als eine rückwärtsgerichtete Gesellschaft auszeichnete, in der die Taten der Altvorderen zu jedem Zeitpunkt fest im kulturellen Gedächtnis der Römer verankert waren. So auch Bleicken, Augustus, 15f.: «Die alten Familien hatten aus ihrer Sicht allen Grund, auf ihre Nobilität stolz zu sein. Seit Jahrhunderten, teils seit den Anfängen der Republik, die über 400 Jahre zurücklagen, waren ihre Ahnen im Staat tätig gewesen, hatten die Stadt verteidigt und ihr Gebiet erweitert, schließlich ganz Italien unterworfen und in ein Bundesgenossensystem verwandelt, um danach über Italien hinauszugreifen und große Teile des Mittelmeerraums ihrer Herrschaft unterzuordnen. [...] Die Cornelier und Fabier, Claudier und Aemilier, die Fulvier und Sempronier, Liciner und Domitier konnten auf zahlreiche berühmte Angehörige ihres Geschlechts zurückblicken, von denen bei jedem Begräbnis eines bedeutsamen Familienmitgliedes Wachsmasken mitgeführt wurden, so dass sie immer gegenwärtig waren.» Ein geachtetes Adelsgeschlecht für Fulvia betonen Hesberg-Tonn, Coniunx Carissima, 77; Fischer, Fulvia und Octavia, 10, bes. Anm. 17.

24. Fulvias Urgroßvater war C. Sempronius Tuditanus (cos. 129). Berühmtheit erlangte er neben der Abhaltung eines Triumphs und der Errichtung einer Ehrenstatue vornehmlich durch das Abfassen mehrerer historischer Werke, vgl. BECK/WALter, Die frühen römischen Historiker, 330-339. Weitere berühmte Mitglieder dieser gens, und damit direkte Vorfahren Fulvias, waren: M. Sempronius Tuditanus (cos. 240, cens. 230), P. Sempronius Tuditanus (cos. 204, cens. 209) und M. Sempronius Tuditanus (cos. 185).

25. Von 322 an sind die Fulvier annähernd durchgehend bis 125 in den Consularfasten vertreten. Dass sie ursprünglich aus Tusculum, einer circa $20 \mathrm{~km}$ südöstlich von Rom gelegen Stadt stammten, belegt Plin. n.h. 7,136. Cicero selbst stellt Fulvias direkte Verbindung zu den tusculanischen Fulviern her, Cic. Phil. 3,16.

26. Cic. Planc. 20. Cicero tätigt diese Aussage zu einem Zeitpunkt, als Fulvia in seiner Überlieferung noch keine Rolle spielte und damit auch kein Grund für ihn bestand, ihre Familie durch verächtliche Bemerkungen herabzuwürdigen.

27. Cic. Phil. 3,16: bonae feminae, locupletis quidem certe. Wann genau der Nachlass ihrer Familie auf Fulvia überging, lässt sich aus den Quellen nicht rekonstruieren, vgl. FISCHER, Fulvia und Octavia, 12. 
und geistigen Fähigkeiten sowie den ihrem Stand entsprechenden Umgangstugenden ausgegangen werden kann.

In Bezug auf Fulvias Qualitäten bei der Haushaltsführung liegt eine Behauptung Ciceros vor, der zufolge «im Hause dieses Menschen [Antonius, S.K.] [...] inmitten von Wollkörben Gold gewogen, Geld gezählt [wurde]». ${ }^{28} \mathrm{Im}$ Unterschied zu Plutarch, der konsequent jede hauswirtschaftliche Betätigung Fulvias negiert, ${ }^{29}$ lässt sich der Bemerkung Ciceros bei aller Verachtung dennoch entnehmen, dass Fulvia zur wirtschaftlichen Produktivität des Hauses beitrug. Entgegen dem vorgegebenen Frauenideal hantierte sie statt mit Wolle mit aurum und pecunia, eine Tatsache, an der Cicero im Kontext der von ihm propagierten Rückbesinnung auf die traditionellen Wert- und Normvorstellungen den schwersten Anstoß nahm. Nichtsdestotrotz verhielt sich Fulvia mit ihren Handlungen für eine Frau des ersten vorchristlichen Jahrhunderts nicht untypisch. Wie viele Standesgenossinnen ihrer Zeit dürfte es für sie eine Selbstverständlichkeit gewesen sein, in Abwesenheit ihres Ehegatten auch dessen Aufgabe zu übernehmen, für das materielle Wohl der Familie zu sorgen, indem sie die Finanzgeschäfte stellvertretend leitete. ${ }^{30}$ Gleichwohl wird sie in solchen Zeiten als Gastgeberin und Ansprechpartnerin der familiären clientela, die angesichts der bedeutenden gesellschaftlichen Positionen ihrer Ehegatten stets recht ansehnlich gewesen sein dürfte, zur Verfügung gestanden haben.

Fulvias geistige Fähigkeiten werden außerdem durch eine von Nepos getätigte Bemerkung belegt, wonach sie «in günstigeren Zeiten ein Grundstück mit bestimmtem Zahlungstermin gekauft hatte». ${ }^{31}$ Die Kürze dieser Aussage darf nicht über ihre semantische Tragweite hinwegtäuschen. Ein Grundstück zu erwerben, setzte ein erhöhtes Handlungsgeschick und Reflexionsvermögen sowie eine gewisse Eigenständigkeit in der Haushaltsund Vermögensverwaltung voraus. Offenkundig scheint Fulvia über solche Fähigkeiten verfügt zu haben, da Nepos neben ihr keine anderen Personen benennt, die unterstützend bei dem Kauf in Erscheinung getreten wären. ${ }^{32}$

28. Cic. Phil. 3,10: at vero huius domi inter quasilla pendebatur aurum, numerabatur pecunia.

29. Plut. Ant. 10,5.

30. Eine solche Situation hatte sich für Fulvia ergeben, als Antonius aufgrund des Mutinensischen Krieges von November 44 bis weit in das Jahr 43 außerhalb Roms agierte. Ebenso wird Fulvia ab dem Sommer 42 - ihr Ehemann hatte gemeinsam mit Octavian Rom verlassen, um gegen die Caesarmörder ins Feld zu ziehen - eigenständig die Vermögensgeschäfte verwaltet haben. Im Übrigen übernahm auch Terentia, Ciceros Frau, die Vermögensverwaltung, als sich ihr Ehemann aufgrund seiner Verbannung außerhalb Roms aufhielt, vgl. ERMETe, Terentia und Tullia, 142-147, 160-162.

31. Nep. 9,5: quin etiam, cum illa fundum secunda fortuna emisset in diem.

32. Dennoch wird, zumindest symbolisch, ein Tutor für die Abwicklung der Vermögensgeschäfte eingesetzt worden sein, vgl. Anm. 9. Dass Fulvia daneben weitere Immobilengeschäfte unterhielt, bei denen sie als alleinige Kaufanwärterin in Aktion trat, belegt App. civ. 4,29,124. 


\section{c) Fulvias Eheschließungen: Motive und Voraussetzungen}

Für Clodius, Curio und Antonius bestanden im Vorfeld vielerlei Gründe, die sie zu einer Eheschließung mit Fulvia veranlassten und diese gleichsam zu einer lukrativen Heiratspartie avancieren ließen. ${ }^{33}$

Für jeden der drei Ehegatten dürfte zunächst aufgrund ihres Alters - alle befanden sich in den Mittdreißigern ${ }^{34}$ - und der ihnen zugetragenen Position innerhalb des römischen Staates die Stammhalterfrage elementar gewesen sein. Während Clodius in diesem Punkt auf Fulvias Jugendlichkeit vertrauen konnte, ${ }^{35}$ wird für Curio und Antonius der Umstand, dass Fulvia in ihrer ersten Ehe bereits Kinder geboren hatte, als wesentlicher Garant für die Zeugung eigener, insbesondere männlicher Nachkommen gegolten haben. ${ }^{36}$ Daneben mussten sich Fulvias pekuniäre Ressourcen sowohl für Clodius, ${ }^{37}$ mehr aber noch für den hoch verschuldeten Antonius als vorteilhaft erweisen. Letzterer hatte im Jahr 46 unter Caesars höchster Missbilligung einen beträchtlichen Schuldenberg angehäuft, den er nun wohl mit Hilfe der finanziellen Mittel seiner Frau zu begleichen hoffte. ${ }^{38}$

Schließlich wird Fulvias Abkunft von zwei berühmten plebeischen Familiengeschlechtern den drei Ehemännern als potenzielles Instrumentarium

33. Fulvias Eheschließung mit Clodius erfolgte einer Aussage Ciceros (Phil. 2,48) zufolge spätestens im Jahr 58, vgl. KRECK, Untersuchungen, 152f.; FISCHER, Fulvia und Octavia, 7-9. Ein Hochzeitsdatum für das Jahr 62 veranschlagt ВАвСоск, The early career, 6, Anm. 14, der auf diese Weise seine Theorie von einer «frühen politischen Karriere» Fulvias zu beweisen glaubt, ohne die relevanten Quellenbelege zu liefern. Unmittelbar nach Clodius' Tod im Jahr 52, spätestens aber im Jahr 51, fand Fulvias zweite Eheschließung mit Curio statt, auf deren bloße Existenz einzig Cicero (Phil. 2,11) verweist. Fulvias Ehe mit Antonius wurde spätestens im Jahr 46 geschlossen, wofür Cic. Phil. 2,77f. spricht. Vgl. dazu die annähernd übereinstimmende Forschermeinung von FörTsch, Die politische Rolle der Frau, 108; KReCK, Untersuchungen, 154; HuZAR, Mark Antony, 99; Fischer, Fulvia und Octavia, 27f. Lediglich Christ, Frauen der Triumvirn, 89, tendiert unbegründet zum Jahr 45.

34. Für Clodius wird eine Geburt um das Jahr 93, für Curio um die Mitte der achtziger Jahre und für Antonius um das Jahr 82 angenommen, vgl. Fischer, Fulvia und Octavia, 9, 19, 25, jeweils mit weiterführender Literatur.

35. Mit ihren etwa 17 Jahren - bleibt man bei einer Eheschließung im Jahr 58 - befand sich Fulvia in einem angemessenen Heiratsalter. Daneben dürfte ihre anzunehmende Jungfräulichkeit ihren Wert als potenzielle Ehefrau erheblich gesteigert haben. Zur Bedeutung der Jungfräulichkeit bei künftigen Ehepartnerinnen vgl. KRAuSE, Verwitwung, 122f. Die Eltern junger Mädchen sahen es daher als ihre vornehmlichste Pflicht an, die Jungfräulichkeit ihrer Tochter durch ständige Überwachung zu bewahren, vgl. Kunst, Livia, 15. Zum herkömmlichen Heiratsalter römischer Töchter vgl. Kunst, Eheallianzen, 36f.

36. Gerade für Antonius wird der Umstand, dass er mit Ende dreißig und nach zwei vorangegangen Ehen, aus denen keines seiner Kinder das Jugendalter überlebte, noch immer nicht auf männliche Nachkommen verweisen konnte, die Sorge um den künftigen Fortbestand der eigenen gens massiv verstärkt haben. Zu Antonius' früheren Ehen siehe Huzar, Mark Antony, 98f.

37. Für ihn war insbesondere die Aussicht auf eine hohe Mitgift sowie auf ein günstiges Erbe entscheidend, vgl. Pomeroy, Frauenleben, 284; Virlouvet, Woman of Passion, 67.

38. Von ihren ersten beiden Ehemännern wird Fulvia, zumindest für ihre Kinder, ein staatliches Vermögen hinterlassen worden sein. Auf jeden Fall dürfte sie die Mitgift aus ihren früheren Ehen gemäß den rechtlichen Vorschriften in vollem Umfang zurückerhalten haben, vgl. Fischer, Fulvia und Octavia, 18. Zur Mitgift als Teil der Witwenversorgung vgl. KRAuse, Wirtschaftliche und gesellschaftliche Stellung, 47-66. Schon Cicero (Phil. 3,16) lässt ein solches Motiv für Antonius anklingen. Dieser Meinung folgten zahlreiche Historiker wie z.B. BАвСоск, The early career, 11; HuzAR, Mark Antony, 66; WelCH, Fulvia and the ghost of Clodius, 192. 
zur Durchsetzung eigener popularer Bestrebungen erschienen sein. Demnach fiel Clodius' Vermählung mit Fulvia genau in jenen Zeitabschnitt, als er im Zuge der angestrebten Bewerbung für das Volkstribunat seinen Übertritt von dem patrizischen in den plebeischen Bürgerstand vollzog. Der nachdrücklichen Profilierung als popularis entsprechend, bemühte er sich anschließend um den Ausbau seiner Akzeptanzbasis innerhalb der plebs urbana sowie seiner Clientelbeziehungen. Es ist offensichtlich, dass ihm eine aus anerkanntem plebeischen Geschlecht stammende Ehefrau in dieser Lage nur von Vorteil sein konnte. ${ }^{39}$ Die in der Folge erfolgreich geführte politische Karriere des Clodius wirkte sich auch auf seinen Nachlass höchst vorteilhaft aus, auf den aber nur derjenige Anspruch erheben konnte, der als rechtmäßiger Nachfolger des Verstorbenen galt. Fulvia nahm diesbezüglich eine Schlüsselposition ein, da sie als Bewahrerin des Andenkens ihres Gemahls faktisch den Zugang zu dessen Vermächtnis darstellte. Eine Heirat mit ihr versprach ihrem zukünftigen Ehepartner daher vor allem politischen Gewinn. Nachdem zunächst Curio als neuer Ehemann Fulvias diesen effektiv bei seiner Bewerbung um das Volkstribunat eingebracht hatte, ${ }^{40}$ konnte auch Antonius das politische Kapital von Clodius' Witwe zu seinem Vorteil nutzen. Wie Clodius und Curio vor ihm befand er sich zur Zeit seiner Eheschließung mit Fulvia in einer einschneidenden Phase seines Lebens, über die Plutarch Auskunft gibt:

Indes scheint ihn doch Caesar dadurch, dass er seine Ausschweifungen nicht ungerügt hingehen ließ, von der unsinnigen und liederlichen Lebensart großenteils zurückgebracht zu haben. Denn er entsagte nun seinem bisherigen Wandel, dachte wieder ans Heiraten und vermählte sich endlich mit Fulvia, der Witwe des Politikers Clodius, [...]. ${ }^{41}$

Die angedeuteten Lebensumstände, in denen sich Antonius im Jahr 47/46 befand, waren für ihn äußerst prekär. Nach einem zuvor glänzenden Aufstieg zum magister equitum und damit zum Stellvertreter Caesars, war er bei diesem aufgrund seines ungezügelten Lebenswandels in tiefe Ungnade gefallen. In der Konsequenz hatte er nicht nur die Bekleidung des Consulats für das Jahr 46 eingebüßt, sondern musste auch auf die Teilnahme an den Feldzügen 46-45 in Africa und Spanien verzichten. ${ }^{42}$ Es ist jene zukunftsunsichere Momentaufnahme, in der Plutarch Fulvia das staatspolitische Parkett betreten lässt. Augenblicklich gibt Antonius daraufhin seinen zuvor praktizierten

39. Von der Forschung wurde dieser Aspekt noch weitestgehend ignoriert. Einzig VirLOUvET, Woman of Passion, 67, macht auf Fulvias politischen Wert für Clodius aufmerksam.

40. Bereits im Jahr 53, nach dem Tod des gleichnamigen Vaters (cos. 76), hatte Curio seine politische Ausrichtung gewandelt und war nach 51 ganz auf die Seite der Popularen gewechselt. Als Volkstribun trat er von nun an als vehementer Unterstützer Caesars auf, vgl. Dettenhofer, Perdita Iuventus, 45-63.

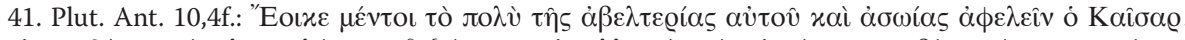

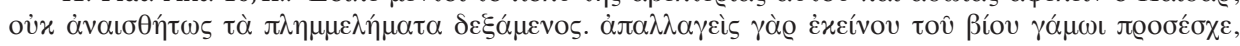

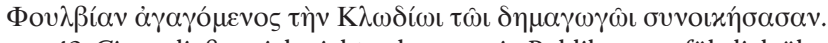

42. Cicero ließ es sich nicht nehmen, sein Publikum ausführlich über den sozialen Abstieg von Antonius zu unterrichten, Phil. 2,67. 
ausschweifenden Lebensstil auf, ordnet seine privaten Verhältnisse neu und verhindert so die dauerhafte Entzweiung zwischen sich und Caesar. Fulvias diesbezügliche Funktion als eine Art Stabilitätsfaktor liegt als Motiv für die Ehe nahe. ${ }^{43}$ Gleichwohl dürfte Fulvia als Witwe von zwei Caesarianern als ein offensichtlicher Indikator und damit als Garantin für eine nun konsequent caesartreue Lebensweise des Antonius gegolten haben. Plutarchs Aussage lässt sogar noch weitreichendere Vermutungen zu. So ist durchaus anzunehmen, dass Caesar selbst die Beziehung zwischen Antonius und Fulvia initiierte, um auf diese Weise Antonius auf den rechten Pfad der Tugend zurück zu lenken. ${ }^{44}$ Da Plutarch jedoch den einzigen Anhaltspunkt für solch eine Vermutung liefert, bleibt sie zuletzt ungeklärt und damit rein spekulativ. ${ }^{45}$ Ebenso ist eine von den Quellen suggerierte Liebeshochzeit ${ }^{46}$ aus historischer Perspektive betrachtet schwerlich nachvollziehbar. Gerade in der Phase der späten Republik folgten Eheschließungen weniger emotionalen denn vornehmlich pragmatischen Beweggründen, weshalb auch alle drei Ehen Fulvias in erster Linie als politische Ehen angesehen werden müssen. ${ }^{47}$

43. Auch Fischer, Fulvia und Octavia, 28, sieht aufgrund der zeitlichen Übereinstimmung einen Zusammenhang zwischen Fulvias Eheschließung mit Antonius und dessen Versöhnung mit Caesar, weist jedoch auf die diesbezüglich differierenden Forschungsmeinungen hin, vgl. ebenda, Anm. 115.

44. Vgl. Virlouvet, Woman of Passion, 71: «Caesar obviously hoped that a woman like Fulvia could keep Antony in line.» Außerdem war Caesar angesichts der instabilen Lage auf loyale und militärisch begabte Gefolgsleute angewiesen. Es konnte ihm folglich nicht daran gelegen sein, einen «Vollblut-Soldat» (FISCHER, Fulvia und Octavia, 28, Anm. 15), wie es Antonius war, wegen derart fahrlässiger Privateskapaden als treuen Anhänger zu verlieren. WELCH, Fulvia and the ghost of Clodius, 190, geht in ihrer Argumentation sogar noch einen Schritt weiter und behauptet, Caesar habe sich erhofft, über Antonius' Ehefrau Fulvia an die clodianische Clientel zu gelangen, um auf diese Weise das Vertrauen der plebs urbana zurück zu gewinnen.

45. Als genauso hypothetisch muss zuletzt auch die wiederholt von einigen Forschern (z.B. BABCOCK, The early career, 25; WELCH, Fulvia and the ghost of Clodius, 194) vertretene Ansicht, Fulvia selbst habe aus politischen Ambitionen eine Heirat mit Antonius fokussiert, betrachtet werden, da sie aufgrund ihres rein teleologischen Charakters jeglicher Beweisbarkeit entbehrt.

46. Cic. Phil. 2, 77f.; Plut. Ant. 10,7-10. Vordergründig dienten Cicero und Plutarch die beschriebenen Episoden dazu, auf Antonius' Frauenunterwürfigkeit und -abhängigkeit hinzuweisen. Zu diesem Zweck stilisierten sie Fulvia zur Männer dominierenden Frau, dazu auch Plut. Ant. 10,5-7. Noch die moderne Forschung folgte dieser antiken Stigmatisierung, wie die Äußerung von HuzAr, Mark Antony, 99, «Fulvia was a mangager, and Antony was manageable», nur allzu deutlich macht. Auch RussELl, Emasculation, passim, spricht in diesem Zusammenhang von einer «emasculation» des Antonius.

47. Dennoch kann angenommen werden, dass es Antonius neben den politischen Vorzügen, die ihm eine Heirat mit Fulvia boten, auch darum ging, sich im Sinne der Familienverbundenheit und Schutzbedürftigkeit dem Schicksal der jungen Witwe und ihren drei minderjährigen Kindern anzunehmen. Ein derart motiviertes Handeln, das letzten Endes vielleicht sogar auf wahren Liebesgefühlen basierte, musste auch Fulvia angesichts der unruhigen Zeiten, in denen sie relativ schutzlos als Witwe mit ihrem Nachwuchs zu leben hatte, vorteilig erscheinen, vgl. Fischer, Fulvia und Octavia, 27. Zu den besonderen Gefahren, denen gerade Witwen oftmals ausgesetzt waren, vgl. KRAUSE, Wirtschaftliche und gesellschaftliche Stellung, 232-243. 


\section{III.2. Fulvia als mater familias}

\section{a) fertilitas: Zeugung legitimer Nachkommen.}

Während ihrer Ehen brachte Fulvia in den Jahren 58 bis 42 insgesamt fünf Kinder zur Welt. Bereits im Jahr 56 gebar sie ihrem ersten Ehegatten Clodius einen Sohn, P. Claudius Pulcher, und damit den ersehnten Stammhalter. ${ }^{48}$ Welche politische Bedeutung dieser Geburt zukam, zeigte sich an jenem schicksalsträchtigen 18. Januar des Jahres 52, als infolge eines Aufeinandertreffens an der Via Appia T. Annius Milo den Tod seines Erzrivalen Clodius veranlasste. Womöglich um die Gefahren eventueller Erbansprüche oder späterer Rachegelüste von vornherein auszuschließen, erwog Milo, auch den damals mit seinem Vater reisenden Claudius umbringen zu lassen. Nur das beherzte Eingreifen eines Sklaven verhinderte Schlimmeres und sicherte so die Weiterführung der gens Claudii Pulchri. ${ }^{49}$ Neben ihrem Sohn brachte Fulvia während dieser Ehe noch ein weiteres Kind, die Tochter Claudia, zur Welt. ${ }^{50}$

Schon ein Jahr nach ihrer zweiten Eheschließung entband Fulvia, wohl um das Jahr 50, erneut einen Sohn, der wie sein Vater den Namen Scribonius Curio erhielt. ${ }^{51}$ Nach dem jähen Tod Curios im August 49 im Africanischen Krieg sollte sich auch diese Geburt als überlebensnotwendig für die väterliche gens, der Scribonii Curiones, herausstellen.

Zum Zeitpunkt ihrer Vermählung mit Antonius befand sich Fulvia schließlich in ihrem 30. Lebensjahr, was ein allmähliches Nachlassen ihrer Gebärfähigkeit durchaus befürchten ließ. Dennoch vermochte sie es, erneut ihrer vordringlichsten Pflicht als Ehefrau nachzukommen. Um das Jahr 45 schenkte sie ihrem Gatten mit M. Antonius Antyllus den ersten männlichen Erben. $^{52}$ Ein weiterer Sohn, Iullus Antonius, folgte im Jahr 42, womit Antonius die Weiterführung seiner gens nun doppelt abgesichert sah. In einer Gesellschaft, in der eine hohe Kindersterblichkeit ein alltägliches Phänomen darstellte, ${ }^{53}$ musste dieses Ereignis mit großer Freude innerhalb der Familie begrüßt worden sein. Zumal die Geburt keineswegs eine Selbstverständlichkeit

48. Das ungefähre Geburtsjahr ergibt sich aus einer Bemerkung von Antonius aus dem Jahr 44, in der er seinen Stiefsohn als puer bezeichnet, welcher folglich zu diesem Zeitpunkt keine 14 Jahre alt gewesen sein kann, Cic. Att. 14,13A.

49. Ascon. 35C,7-11. In Ciceros Schilderung (Mil. 28.55) befindet sich Clodius' Sohn nicht unter den Begleitern.

50. Den einzigen Anhaltspunkt für eine annähernde Bestimmung von Claudias Geburt im Jahr 55 stellt ihre Vermählung mit Octavian dar, die im Zuge des abgeschlossenen «Zweiten Triumvirats» im Jahr 43 vollzogen wurde und bei der sie wenigstens zwölf Jahre alt gewesen sein muss, vgl. FISCHER, Fulvia und Octavia, 14 .

51. Zu ihm vgl. Fischer, Fulvia und Octavia, 20 .

52. Ein Geburtsjahr 45 ergibt sich aus der Tatsache, dass M. Antonius Antyllus nach der Ermordung Caesars im März 44 laut Fischer, Fulvia und Octavia, 28, Anm. 114, "wohl mindestens ein Jahr» alt gewesen sein muss, um zu den Mördern des Dictators als Geisel und Bürge auf das Kapitol gebracht zu werden, Cic. Phil. 1,2.31; 2,90; Vell. 2,58,3; Cass. Dio 44,34,6; Plut. Ant. 14,2.

53. Vgl. Kunst, Eheallianzen, 36. 
darstellte, zieht man in Betracht, dass es für Fulvia bereits die fünfte Entbindung war, die sie mit Mitte dreißig zu bewältigen hatte. ${ }^{54}$ Insgesamt betrachtet dürfte Fulvia aufgrund dieser Leistung als respektable Persönlichkeit innerhalb der römischen Gesellschaft wahrgenommen worden sein. Auch in der wenig schmeichelhaften Aussage des Velleius Paterculus, Fulvia sei eine Person gewesen, «an der nichts Weibliches war als ihr Körper», ${ }^{55}$ lässt sich in diesem Kontext sogar eine gewisse Wertschätzung ablesen. Denn auch wenn ihr durch die Bemerkung ein weibliches Verhalten rigoros in Abrede gestellt wird, so weise sie dennoch ihre Anatomie und damit ihre Reproduktionsfunktionalität ganz eindeutig als Frau aus.

\section{b) Verhalten als Mutter: Schutz und Erziehung der Kinder}

Bis zu seiner Bewerbung um die Praetur des Jahres 52 hielt sich Clodius, von gelegentlichen Reisen in Italien abgesehen, in Rom auf, wo er die sittliche und moralische Erziehung seines Sohnes Claudius wohl größtenteils selbst übernahm. Seine Tochter Claudia hingegen wird maßgeblich unter der Obhut von Fulvia gestanden haben, die deren Betreuer anleitete und ihre pädagogischen Maßnahmen überwachte. Dabei ist sogar anzunehmen, dass sie aufgrund ihres jugendlichen Alters die Unterstützung von Verwandten, wohl in erster Linie die ihrer Mutter, erhielt. ${ }^{56}$ Auch wenn Fulvia nach Clodius' Tod sicherlich die Erziehung beider Kinder oblag, ist insbesondere für den jungen Claudius anzunehmen, dass einer von Clodius' Brüdern, Appius oder Gaius, seinen Einfluss als dessen Vormund geltend machte und seinen Neffen auf eine spätere politische Karriere entsprechend vorbereitete. ${ }^{57}$

Der jäh ausgebrochene Bürgerkrieg zwischen Caesar und Pompeius im Jahr 49 setzte auch dem keine zwei Jahre zuvor geschlossen neuen Ehebündnis Fulvias ein abruptes Ende. Curio, als caesarischer Legat erst auf Sizilien, dann in Africa kämpfend, hielt sich ab April 49 bis zu seinem Tod im August desselben Jahres permanent außerhalb Roms auf. ${ }^{58}$ In den

54. Zu den Gefahren, die eine Geburt im antiken Rom bedeutete, vgl. Kunst, Livia, 35: «Die gebärfähigen Jahre gehörten zu den gefährlichsten für Leben und Gesundheit der Frauen.»

55. Vell. 2,74,3: nihil muliebre praeter corpus gerens.

56. Fulvias Mutter Sempronia kann frühestens in der zweiten Jahreshälfte 52 verstorben sein, da sie im April desselben Jahres noch im Gerichtsprozess gegen Milo aussagte, Ascon. 40C,18-21.

57. P. Clodius stammte aus einer Consularsfamilie. Wie er selbst bestritten auch seine beiden Brüder den cursus honorum. Es ist daher nur konsequent anzunehmen, dass Clodius für seinen Sohn eine eben solche Karriere anstrebte, zumal ihm dafür die finanziellen Voraussetzungen gegeben waren. Für eine Ämterlaufbahn des Claudius erbringt Wiseman, Pulcher Claudius, bes. 211-213 den epigraphischen Beweis und nimmt darüber hinaus an, dass er zwei Kinder hinterließ, vgl. 213-217. Widersprechend Val. Max. 3,5,3, wonach der junge Claudius in seiner Jugend ein zügelloses Leben führte, an dem er schließlich zugrunde ging.

58. Curio sowie Fulvias späterer Ehemann Antonius waren maßgeblich an den Aktionen kurz vor Caesars Rubiconüberschreitung am 11. Januar 49 beteiligt. Für einen zusammenfassenden Abriss zu den Ereignissen, die zum Ausbruch des Bürgerkrieges führten, mit den wichtigsten Quellen- und Literaturangaben siehe Dettenhofer, Perdita Iuventus, 139-146. 
anhaltenden Bürgerkriegswirren blieb Fulvia mit drei Kindern, eines davon im Säuglingsalter, allein in Rom zurück, wo sie sich - nun bereits zum zweiten Mal Witwe eines pflichterfüllten Caesarianers - zu dieser Zeit nicht sicher fühlen konnte. Zwar unterstand Italien Caesars Kontrolle, doch galt dessen Position auch nach der Ermordung von Pompeius im September 48 keinesfalls als gefestigt. ${ }^{59}$ Dass Fulvia ihren Kindern in dieser höchst angespannten Lage Schutz gewährte und für ihre Sicherheit eintrat, darf als wahrscheinlich gelten. In jedem Fall stellte sie die wichtigste Bezugsperson für ihre Kinder dar, die damit zwangsläufig ihrem unmittelbaren Einfluss unterstanden. ${ }^{60}$

Spätestens mit ihrer Heirat im Jahr 46 hatte sich Antonius Fulvias und ihrer Kinder angenommen. Zumindest für die zwei Söhne, Claudius und Curio, stand er Fulvia erzieherisch zur Seite, wie es ein überlieferter Briefwechsel zwischen Antonius und Cicero vom April 44 bezüglich des damals zwölfährigen Claudius Pulcher nahe legt. ${ }^{61}$ Dass er seine Stiefkinder darüber hinaus als wichtige Faktoren für die Durchsetzung eigener politischer Interessen erkannte, wird am Beispiel von Claudia, Fulvias einziger Tochter, besonders augenfällig. Im November 43 wurde sie im Zuge des zwischen Antonius, Octavian und Lepidus geschlossenen «Zweiten Triumvirats» als Garantin des Einvernehmens zwischen ihrem Stiefvater und Octavian mit letzterem verheiratet. ${ }^{62}$

Wie bereits in ihren früheren Verbindungen blieb Fulvia auch während der Ehe mit Antonius über lange Zeiträume auf sich allein gestellt. Nicht nur, dass sie in diesen Phasen die Erziehung von zuletzt fünf Kindern in Eigenverantwortung leitete und überwachte: Während Antonius' erster längerer Abwesenheit in den Monaten von November 44 bis April 43 hatte sie darüber hinaus unter empfindlichen Repressalien zu leiden und sah sich sogar mit Morddrohungen gegen ihre Nachkommen konfrontiert. Trotz nur geringer Unterstützung in dieser äußerst bedrohlichen Situation gelang es ihr dennoch, ihre Kinder vor tätlichen Übergriffen zu bewahren und für ihre Sicherheit zu sorgen. ${ }^{63}$

59. Zur Lage in Italien vgl. Christ, Krise und Untergang, 366-378; BaltrusCH, Caesar, 107f., 114-116.

60. Ohne jede Beweisgrundlage gibt Virlouvet, Woman of Passion, 70, an, dass Fulvia nach dem Eintritt ihrer zweiten Witwenschaft mit ihrer Mutter zusammenlebte. Da jedoch noch nicht einmal gesichert davon ausgegangen werden kann, dass Fulvias Mutter zu diesem Zeitpunkt überhaupt noch lebte, muss diese Behauptung als rein spekulativ zurückgewiesen werden, vgl. Anm. 56.

61. Cic. Att. 14,13A,2f.; 14,13B,4.

62. Die antiken Historiker schwanken in ihrem Urteil über den Hauptinitiator dieser politischen Allianz. Eine Heirat auf Drängen der Soldaten wird angegeben von Vell. 2,65,2; Suet. Aug. 62,1; Plut. Ant. 20,1f. Hingegen sieht Cass. Dio 46,56,3f. Antonius als maßgeblichen Initiator. Nichtsdestotrotz ist Fulvias direkte Zustimmung zum Ehebund ihrer Tochter durchaus anzunehmen, vgl. Fischer, Fulvia und Octavia, 37. Schließlich stand den Müttern oftmals eine Mitsprache bei der Verlobung ihrer Kinder, besonders der Töchter, zu. Beispiele bei Ermete, Terentia und Tullia, 51, Anm. 187, 71; Deissmann, Aufgaben, 518. Für die zwei Jahre später von Octavian veranlasste Scheidung wird Fulvia allerdings einhellig als Hauptschuldige in den Quellen angeführt, Cass. Dio 48,5,3; Suet. Aug. 62,1. So soll sie aufgrund von Auseinandersetzungen mit dem Schwiegersohn zur Entzweiung des Paares maßgeblich beigetragen haben, was angesichts des stark augusteischen Charakters der Überlieferung zumindest fragwürdig erscheint.

63. Nep. 9,2-5. Hinzu kamen die Hetzaktionen Ciceros, die er öffentlich nicht nur gegen Antonius, sondern gegen dessen ganze Familie richtete, beispielgebend Cic. Phil 4,10. 
Kurz nach der Geburt des zweiten Sohnes Iullus Antonius ließ Antonius seine Frau erneut in Rom zurück. Bis sich die Eheleute ein letztes Mal im März 40 nach der Niederlage von Perusia in Athen wieder sehen sollten, unterstanden die Kinder einzig der Aufsicht ihrer Mutter, womit sie unweigerlich in die Geschehnisse um den Perusinischen Krieg der Jahre 41/40 involviert waren. So berichtet Appian, wie Fulvia ihre beiden, von Antonius abstammenden Söhne dessen Bruder Lucius überantwortete, um sie dem Heer vorzuführen. Durch den Anblick der Kinder sollte dieses nämlich daran erinnert werden, dass Antonius und nicht etwa Octavian es gewesen war, der die Schlacht um Philippi 42 gewonnen hatte und dem sie nun die zugewiesenen Ländereien verdankten. ${ }^{64}$ Aufgrund der angespannten Lage, die sich durch die von Octavian vorangetriebene Veteranenansiedlung in Italien weiter zuspitzte, erscheint es trotz der Schilderungen Appians dennoch höchst unwahrscheinlich, dass sich Lucius in solch einer Situation einzig durch den Willen einer Frau, seiner Schwägerin, leiten ließ ${ }^{65}$ Vielmehr ist anzunehmen, dass Lucius selbst, möglicherweise durch den Ratschlag von Fulvia animiert, die Entscheidung zu dem psychologisch-strategischen Einsatz von Antonius' Söhnen fasste. Vor den Soldaten agierte Lucius schließlich als Interessenvertreter seines Bruders und bedurfte daher dringend einer Rechtfertigung für seine Handlungen. Durch den gemeinsamen Auftritt mit seinen Neffen, den eigentlichen Stellvertretern ihres Vaters, war ihm eine solche Legitimationsgrundlage symbolträchtig an die Hand gegeben. ${ }^{6}$

\section{c) pudicitia und castitas: Sittliche und moralische Reinhaltung der Familie}

Einzig von Cicero liegen konkrete Hinweise vor, wonach Fulvia während ihrer Ehe mit Clodius ein ehebrecherisches Verhältnis mit dessen damaligem Freund und Unterstützer Antonius, Fulvias späterem Ehemann, unterhalten haben soll. ${ }^{67}$ Geht man von der Richtigkeit des gegen Fulvia erhobenen

64. App. civ. 5,19,76.

65. Auch Cass. Dio 48,4,1-6 suggeriert eine Dominanz Fulvias gegenüber ihrem Schwager Lucius (cos. 41).

66. Mit App. civ. 5,14,56: «Sie führten nun Fulvia und die Kinder des Antonius vor die Soldaten hin und flehten sie gar mit aufreizenden Worten an, es nicht geschehen zu lassen, dass Antonius seines Ruhmes

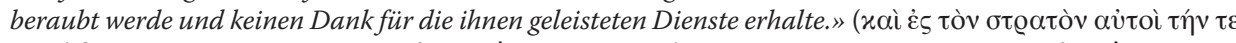

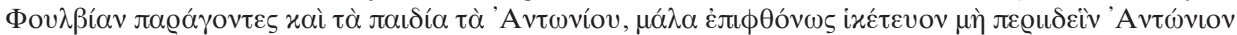

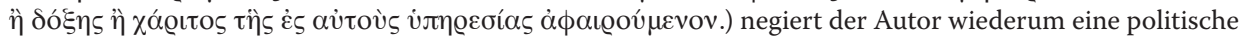
Eigeninitiative Fulvias, indem seine Darstellung impliziert, dass Fulvia «gar nicht aus eigenem Antrieb handelte», Kunst, Livia, 70. Diese Ansicht widerspricht der allgemeinen Forschermeinung, wonach gerade diese Aktion einen eindeutigen Beleg für Fulvias angeblich politische Methode darstelle, vgl. FISCHER, Fulvia und Octavia, 43; Bauman, Women and Politics, 87.

67. Cic. Phil. 2,48.99. Eine mögliche Erklärung für Ciceros Argumentationsweise liefert KRAUSE, Verwitwung, 145: «Die Heiratskandidaten mögen häufig aus dem Freundes- und Bekanntenkreis des verstorbenen Ehemannes gekommen sein; die Bekanntschaft erleichterte die Anbahnung von Kontakten zwischen Witwe und Ehebewerber. Zum Teil erklären sich so die gegen Witwen erhobenen Vorwürfe, (angeblich) vor dem Tod des Mannes gepflegten ehebrecherischen Verkehr nach seinem Tod offen fortzusetzen.» 
Vorwurfs aus, konnte ihr ein solches Verhalten von den Zeitgenossen als Verstoß gegen die pudicitia angelastet werden. ${ }^{68}$

Andererseits entsprach sie dem weiblichen Ideal der castitas, da sie bereit war, die sexuellen Zügellosigkeiten ihres Gatten zu tolerieren. Eindrucksvoll lässt sich dies am Beispiel des Perusinischen Kriegs nachweisen. Von Appian als Hauptagitatorin der Auseinandersetzung beschuldigt, wird Fulvia vorgeworfen, die Feindschaft mit Octavian aus dem vornehmlichen Grund gesucht zu haben, die Affäre ihres Ehemanns mit der ägyptischen Königin Kleopatra VII. zu unterbinden. ${ }^{69}$ In einem von Martial überlieferten Epigramm spielt diese Affäre jedoch noch gar keine Rolle. Stattdessen habe Fulvia den Krieg um Perusia wegen Antonius' Affäre mit Glaphyra, der Mutter des von ihm eingesetzten Klientelkönigs in Kappadokien, begonnen, womit sich ihre Eifersucht gegenüber Kleopatra als kriegsauslösendes Moment hinlänglich widerlegen lässt. $^{70}$ Angesichts von Fulvias Engagement während der Auseinandersetzungen um Perusia muss sogar betont werden, dass sie sich, trotz der diversen, ihren Ehemann betreffenden Gerüchte, die anscheinend in dieser Phase den Klatsch der römischen Oberschicht bewegten, dennoch mit ganzer Kraft für die Interessen ihres Mannes einsetzte und damit, ungeachtet seiner ehelichen Untreue, die moralische Reinhaltung innerhalb der Familie auch in Antonius' Abwesenheit weiterhin aufrecht erhielt.

\section{d) pietas und fides: die kompromisslose Gefährtin}

Alle drei Ehen Fulvias waren von einer tiefgehenden pietas und fidesVerantwortung ihren Ehemännern gegenüber gekennzeichnet. Das Verhältnis zwischen Fulvia und Clodius wird von der Forschung gemeinhin als harmonisch beschrieben. Diese Behauptung stützt sich auf zwei von Cicero getätigte Aussagen, wonach Fulvia ihren Mann stets auf dessen Reisen begleitet haben soll. ${ }^{71}$ Mit der gleichen Loyalität, die sie durch ein derartiges Verhalten demonstrierte, wird Fulvia ihrem Ehemann auch in anderen Lebensbereichen zur Seite gestanden haben. Zumindest ist davon auszugehen, dass sie die politischen Entscheidungen ihres Mannes mittrug, sich für dessen Interessen einsetzte und ihm Unterstützung angedeihen ließ ${ }^{72}$ Dabei scheint sie - ihre

68. Verheirateten Frauen war es strikt untersagt, Liaisons außerhalb der Ehe zu pflegen. Anders verhielt es sich mit den Ehemännern, denen es durchaus gestattet war, sexuelle Kontakte außerhalb der Ehe zu unterhalten. Zur Begründung vgl. Pomeroy, Frauenleben, 243.

69. App. civ. 5,19,75.

70. Martial. 11,20,3-8. Das Epigramm soll Octavian zur Zeit des Perusinischen Krieges selbst verfasst haben. Zu seiner inhaltlichen Deutung siehe Kunst, Livia, 72; KRECK, Untersuchungen, 192f.

71. Cic. Mil. 28.55. Für eine harmonische Ehe sprechen BABCOCK, The early career, 12; KRECK, Untersuchungen, 153; Christ, Frauen der Triumvirn, 92; FISCHER, Fulvia und Octavia, 13.

72. Vgl. Ermete, Terentia und Tullia, 80; Christ, Frauen der Triumvirn, 92; Fischer, Fulvia und Octavia, 17. 
Reisetätigkeit ausgenommen - stets innerhalb der domus agiert zu haben. ${ }^{73}$ Erst nach Clodius' Ermordung tritt sie dann auch öffentlich in Erscheinung. So soll sie zunächst unter Wehklagen die zahlreichen Wunden ihres Gatten, der im Atrium des Hauses aufgebahrt lag, zur Schau gestellt haben..$^{74}$ Die Frage, wie sehr Fulvia in dieser Situation durch ihr aufreizendes Gebaren den Zorn der Menge bewusst zu provozieren beabsichtigte, ist allenfalls spekulativ zu beantworten. Fest steht allerdings, dass direkt nach der Erschlagung des Clodius Unruhen ausbrachen, an deren Zustandekommen ihr von der modernen Forschung immer wieder zumindest eine Teilschuld angelastet wird..$^{75}$ Ihren zweiten öffentlichen Auftritt absolvierte Fulvia wenige Monate später, als sie als Zeugin vor Gericht gegen den Mörder ihres Mannes, T. Annius Milo, aussagte. Wie im beschriebenen Fall zuvor soll sie auch in dieser Situation die Gemüter der Anwesenden durch ihr Auftreten dermaßen erregt haben, dass sie entscheidend zur Verurteilung Milos beitrug. ${ }^{76}$ In beiden beschriebenen Begebenheiten hatte sie durch ihr Verhalten jedermann vor Augen geführt, dass sie ihrem Ehemann Clodius auch über dessen Tod hinweg die gebührende pietas angedeihen ließ.77

Schon wie in ihrer ersten Ehe begleitete Fulvia auch Antonius gelegentlich auf dessen Ausflügen außerhalb Roms. Eine hierfür markante Episode bezieht sich auf jene Reise, die das Ehepaar im Herbst 44 gemeinsam ins Heerlager nach Brundisium unternahm, wo Antonius seine ihm vom Senat bestimmten vier macedonischen Legionen in Empfang nahm. ${ }^{78}$ Die Treue der Soldaten

73. Jedenfalls liegen keine Anhaltspunkte in der Überlieferung vor, die ein Zuwiderhandeln Fulvias dokumentieren. In diesem Zusammenhang sei daran erinnert, wie rigoros Cicero mit Clodia, Clodius' Schwester, verfuhr, nachdem er 57 aus dem Exil nach Rom zurückgekehrt war. Seit dieser Zeit standen sich Cicero und Clodius in offener Feindschaft gegenüber. Mit seiner Behauptung, Clodia treibe Inzest mit dem eigenen Bruder (Cic. dom. 25.92; Sest. 16.116; Mil. 73.75; har. 38.39.59), zielte Cicero in erster Linie darauf ab, das Ansehen seines Widersachers Clodius neben der politischen Verunglimpfung auch auf moralischer Ebene zu schmälern. Außerordentlich drastisch hat es GüNTHER, Sexuelle Diffamierung, 229, formuliert: "Cicero ging in seinem Gerede über Clodia einen Schritt weiter als dies üblicherweise geschah, indem er, um den eigentlichen politischen Kontrahenten, Clodius Pulcher, zu treffen, dessen Schwester Clodia verbal >abschlachtete‘.» Als Schlussfolgerung bleibt festzuhalten, dass zu diesem Zeitpunkt Clodia Cicero augenscheinlich vielmehr Angriffspotenzial bot als Clodius' Ehefrau Fulvia.

74. Ascon. 32,18-22. Bei App. civ. 2,21,77f. bleibt Fulvia hingegen unerwähnt. Nicht von allen Forschern wird die Meinung geteilt, dass es sich bei dieser Begebenheit um einen öffentlichen Auftritt handelt, vgl. Dixon, A family business, 93; Virlouvet, Woman of Passion, 68. Dem ist entgegenzuhalten, dass Fulvia zwar in der eigenen domus, aber dennoch vor einer beträchtlichen Menge anwesender Zuschauer agierte, vgl. Fischer, Fulvia und Octavia, 16. Den Vorfall gänzlich unerwähnt lässt beispielsweise SCHUBERT, Homo politicus, passim.

75. Cass. Dio 40,49,1-5; App. civ. 2,22,79-83. Eine Schuld Fulvias wird angenommen von BABCOCK, The early career, 21; Kunst, Livia, 68.

76. Ascon. 40C,18-21. Schließlich konnte auch Cicero, der als Verteidiger des Angeklagten aufgetreten war, eine Verurteilung seines Mandanten nicht mehr verhindern: Im April 52 wurde Milo mit überwiegender Mehrheit für schuldig befunden und zur Strafe nach Massilia verbannt, Cass. Dio 40,54,1-4; Liv. per. 107.

77. Bis zum Jahr 44 findet Fulvia in der antiken Überlieferung keine weitere Erwähnung, was die Vermutung nahe legt, dass sie sich nach diesen Vorkommnissen augenblicklich in die domus zurückzog, vgl. Anm. 73.

78. Dabei handelte es sich um die Legionen, die Caesar bereits für seinen geplanten Partherfeldzug gerüstet hatte. 
zu ihrem Feldherrn war bei dessen Ankunft jedoch stark erschüttert, so dass Antonius sich gezwungen sah, die mutmaßlichen Rädelsführer der Meuterei töten zu lassen. Cicero und Cassius Dio berichten in diesem Zusammenhang, wie auch Fulvia den Hinrichtungen beiwohnte, indem sie völlig regungs- und teilnahmslos das blutige Schauspiel beobachtet haben soll. ${ }^{79}$ Beiden Autoren diente diese Begebenheit dazu, die Grausamkeit Fulvias exemplarisch zu illustrieren, denn augenscheinlich unterließ sie es, beschwichtigend auf ihren Mann einzuwirken und damit die disziplinierenden Gewaltakte gegen die eigenen Truppen zu verhindern. ${ }^{80}$ Andererseits gab sie durch die von ihr demonstrierte Hartherzigkeit ebenso deutlich zu verstehen, dass sie kompromisslos hinter der Entscheidung ihres Mannes stand, womit sie sich letzten Endes ganz und gar seiner Autorität verpflichtet fühlte. ${ }^{81}$

Auch als sich zum Ende des Jahres 43 eine Gruppe vermögender Frauen hilfesuchend an die weiblichen Angehörigen der Triumvirn gewandt hatte, um gegen die Entrichtung eines Kriegsbeitrags zu protestierten, soll sich Fulvia als Einzige unbarmherzig gezeigt und die Betroffenen schroff an der Tür zurückgewiesen haben. Erneut wurde ihr daraufhin vorgeworfen, nicht mäßigend auf ihren Mann eingewirkt und damit die anschließende Demonstration der Frauen auf dem Forum verursacht zu haben. ${ }^{82}$ Auch wenn Fulvias Verhalten also abermals negativ bewertet wurde, zeigte sie in dieser Situation letztlich wieder nur ihren unbeugsamen Willen, an den politischen Überzeugungen ihres Mannes festzuhalten. ${ }^{83}$

Ähnlich konsequent hatte sich Fulvia wenige Monate zuvor während des Mutinensischen Kriegs verhalten, als Cicero den Senat zu überzeugen suchte, den von Rom abwesenden Antonius zum hostis zu erklären. Appian berichtet, wie Fulvia eine Ächtung unter allen Umständen verhindern wollte, indem sie in Begleitung von Antonius' Mutter Iulia, des Sohnes Antyllus sowie weiterer Verwandter und Freunde die ganze Nacht vor der entscheidenden Senatssitzung um Gnade bei den führenden Familien Roms ersuchte und noch am darauf folgenden Morgen das Mitleid der Senatoren auf dem Weg in die Curie durch Klagerufe und Jammergeschrei hervorzurufen hoffte. ${ }^{84}$ Auch wenn Fulvia Antonius auf diese Weise letztlich nur eine Atempause

79. Cic. Phil. 3,4; 5,22; 13,18; Cass. Dio 45,13,2 (die erste Erwähnung Fulvias überhaupt); 45,35,2f. Zum Sachverhalt vgl. außerdem App. civ. 3,40,164; 3,43f., wo Fulvia auffälligerweise unerwähnt bleibt. Interessant ist auch die Rede des Piso gegen Cicero, in der er das Vorgehen von Antonius gegen seine meuternden Soldaten verteidigt, App. civ. 3,56,230-232.

80. Trotz ihres passiven Verhaltens (dem widerspricht DEBRUNNER HALL, Eine reine Männerwelt?, 214) musste Fulvias bloße Anwesenheit im Heerlager den Zeitgenossen als Grenzüberschreitung erscheinen, die deswegen entsprechend geahndet und Fulvia wie Antonius gleichermaßen zur Last gelegt wurde.

81. Ähnlich argumentierend FörTsCH, Die politische Rolle der Frau, 110; KRECK, Untersuchungen, 167; Fischer, Fulvia und Octavia, 33.

82. App. civ. 4,32,135-34,146.

83. Auch Kunst, Livia, 69, betont, dass Fulvia «mit dieser Haltung ihren Mann weit kompromissloser [unterstützte] als die anderen Frauen ihre männlichen Verwandten». Ähnlich FöRTSCH, Die politische Rolle der Frau, 110f.; KRECK, Untersuchungen, 175; CHRIST, Frauen der Triumvirn, 90.

84. App. civ. 3,51,211f.; 3,58,242. 
verschaffen konnte, zeigte ihr traditionskonformes, couragiertes Engagement doch den hohen Einsatz, den sie in dieser brisanten Situation für ihren Mann bereit war zu leisten.

Am kompromisslosesten zeigte sich Fulvia schließlich im Perusinischen Krieg 41/40, indem sie selbstständig Truppen aushob, Marschbefehle erteilte und Losungen ausgab. ${ }^{85}$ Auch wenn sie bei all ihren militärischen Aktionen stellvertretend für Antonius auftrat, um damit seinen Machtverlust in der Heimat zu verhindern, hatte sie durch dieses - in römischen Augen ungeheuerliche Fehlverhalten ganz eindeutig «den Bogen des gesellschaftlich Erträglichen endgültig überspannt.» ${ }^{86}$

\section{ZuSAMMENFASSUNG}

Fulvia nahm unter den Frauen der römischen Führungsschicht der späten Republik eine herausgehobene Stellung ein. Diese resultierte aus einem herkunftsgebundenen Status, der ihr nacheinander die Heirat mit drei ranghohen Politikern ermöglichte. Unweigerlich war sie damit in die fundamentalen Zerfallsprozesse involviert, die sich am Ausgang der Römischen Republik auf allen Ebenen des gesellschaftlich-politischen Lebens abspielten. Als Reaktion auf das desolate Staatsgefüge wurde ein idealisiertes weibliches wie männliches Rollenkonstrukt als übergeordnetes Leitbild vorgegeben, das jede Beurteilung menschlichen Handels fortan bestimmte. Auch Fulvias Auftreten konnte vor diesem Hintergrund entweder nur positiv oder nur negativ gedeutet werden, eine via media war von vornherein ausgeschlossen. Schon ihre Mitmenschen schrieben Fulvia innerhalb dieses vordefinierten Beurteilungsspektrums eine überwiegend männlich konnotierte Verhaltensweise zu - eine Haltung, die die historische Meinung zu ihr bis heute maßgeblich beeinflusst hat.

Wie die vorliegende Analyse allerdings verdeutlicht, greift diese Charakterisierung eindeutig zu kurz. Stattdessen konnte nachgewiesen werden, dass Fulvia die in ihrer Zeit geltenden weiblichen Normvorstellungen an eine matrona Romana sehr wohl zu erfüllen vermochte. Als filia familae eines aristokratischen Plebeierhauses war sie in der Lage, eine ehrbare Herkunft, ein stattliches Vermögen sowie eine adäquate Erziehung vorzuweisen, womit sie zu jeder Zeit ausreichend Anreize bot, als attraktive Heiratspartie angesehen zu werden. Auch in Bezug auf die Rollenerwartung an eine mater familias

85. App. civ. 5,33,130; Cass. Dio 48,10,3f.; Plut. Ant. 28,1. Es scheint so, dass Fulvia selbst noch vor das belagerte Perusia zog, zumindest lassen dies die vor dem heutigen Perugia gefundenen Schleuderbleie (glandes) vermuten, CIL XI $\mathrm{X}_{2}, 6721$ Nr. 5 und Nr. 14. Zur Rolle Fulvias im Perusinischen Krieg vgl. exemplarisch Fischer, Fulvia und Octavia, 40-47, mit ausführlichen Quellen- und Literaturverweisen.

86. Hesberg-Tonn, Coniunx Carissima, 82f. Dazu Flor. 2,16,5; Vell. 2, 74,3; Val. Max. 3,5,3, die ein «Zerrbild einer androgynen Frau [zeichneten], die das traditionelle Ideal einer häuslichen lanificia konterkarierte und statt dessen das Betätigungsfeld männlicher virtus usurpierte: Macht, Politik und Krieg.», Fischer, Fulvia und Octavia, 44. Vgl. auch Ermete, Terentia und Tullia, 86. 
wurde Fulvia den Ansprüchen an eine vorbildhafte Ehefrau und Mutter in großen Teilen gerecht. Mit der Geburt von fünf Kindern hatte sie jedem ihrer Ehemänner ein Weiterbestehen der eigenen gens ermöglicht. Darüber hinaus bewies sie in all ihren Ehen, dass sie stets eine zuverlässige Konstante im Leben ihrer Ehegatten darstellte. Sie zeigte sich verantwortlich für die Erziehung und den Schutz der Kinder, übernahm in zwingenden Situationen die organisatorische Verwaltung der domus sowie die Aufrechterhaltung der Clientelbeziehungen und trat in konsequenter Manier für die Interessen und Ziele ihrer Ehemänner ein. Einzig der Vorwurf eines ehebrecherischen Verhaltens während ihrer Verbindung mit Clodius Pulcher könnte ihr in diesem Zusammenhang als weibliches Fehlverhalten ausgelegt werden.

Wie entschlossen sie letztlich war, ihren Ehemännern die geschuldete pietas und fides zu erweisen, bezeugen hinlänglich ihre Auftritte in der Öffentlichkeit, die sie vehement in Männerdomänen vordringen ließen. Während sie im Gericht und in der Politik ihre Grenzen weitestgehend zu wahren wusste, hatte sie mit ihrem Eintritt in die militärische Sphäre eine deutliche Grenzüberschreitung vollzogen, wofür es bisher keinen Präzedenzfall gab. Dennoch galten auch ihre diesbezüglich gezeigten ehrgeizigen Aktionen letzten Endes einzig der Unterstützung ihres Ehemanns Marcus Antonius, der ihr diesen Handlungsspielraum überhaupt erst ermöglicht hatte.

Angesichts der vorstehenden Tatsachen lässt sich die vormalige Ansicht von Fulvia als «Mannweib» nicht länger aufrechterhalten. So kann ihr das in diesem Zusammenhang gezeigte Verhalten nur bedingt negativ ausgelegt werden, da bestimmte Zwangslagen ihr bewusstes Agieren in der Öffentlichkeit immer wieder erforderlich machten, um bis zuletzt ihren Pflichten als Ehegattin nachzukommen. Die individuellen Wege, die Fulvia in diesem Sinne mit energischer Hingabe beschritt, sind somit letzten Endes wiederum auf die Ausgestaltung ihrer Rolle als Ehefrau und Mutter zurückzuführen.

\section{BiBLIOGRAPHIE}

BABCOCK, Charles L.: «The early career of Fulvia», in: AJPh, 86 (1965), 1-32.

Baltrusch, Ernst: Caesar und Pompeius, Darmstadt, 2004.

Bauman, Richard A.: Women and Politics in Ancient Rome, London / New York, 1994.

Beck, Hans, Walter, Uwe (Hrsg.): Die frühen römischen Historiker, Bd. I: Von Fabius Pictor bis Cn. Gellius, Darmstadt, 2001.

Bleicken, Jochen: Augustus. Eine Biographie, Sonderausgabe, Berlin, 2000.

Christ, Karl: «Die Frauen der Triumvirn», in: Ders.: Von Caesar zu Konstantin. Beiträge zur Römischen Geschichte und ihrer Rezeption, München, 1996, 85-102.

Christ, Karl: Geschichte der römischen Kaiserzeit. Von Augustus bis zu Konstantin, München, ${ }^{5} 2005$. 
CHRIST, KARL: Krise und Untergang der römischen Republik, Darmstadt, ${ }^{6} 2008$.

Culham, Phyllis: «Women in the Roman Republic», in: Flower, Harriet I. (Hrsg.): The Cambridge Companion to the Roman Republic, Cambridge, 2004, 139-159.

Debrunner Hall, Margaretha: «Eine reine Männerwelt? Frauen um das römische Heer», in: Dettenhofer, Maria (Hrsg.): Reine Männersache? Frauen in Männerdomänen der antiken Welt, Köln u.a., 1994, 207-228.

Deissmann, Marie-Luise: «Aufgaben, Rollen und Räume von Mann und Frau im antiken Rom», in: Martin, Jochen, Zoepfel, Renate (Hrsg.): Aufgaben, Rollen und Räume von Frau und Mann, Teilband 2, München, 1989, 501-564.

Dettenhofer, Maria H.: «Zur politischen Rolle der Aristokratinnen zwischen Republik und Prinzipat», in: Latomus, 51 (1992), 775-795.

Dettenhofer, Maria H.: Perdita Iuventus. Zwischen den Generationen von Caesar und Augustus, München, 1992.

Dixon, SuzAnNe: «A family business: Women's role in patronage and politics at Rome 80-44 B.C.», in: Classica et Mediaevalia, 34 (1983), 91-112.

ERMEte, Karen: Terentia und Tullia - Frauen der senatorischen Oberschicht, Frankfurt a.M., 2003.

Fischer, Robert A.: Fulvia und Octavia. Die beiden Ehefrauen des Marcus Antonius in den politischen Kämpfen der Umbruchszeit zwischen Republik und Principat, Berlin, 1999.

FÖRTSCH, BARBARA: Die politische Rolle der Frau in der römischen Republik, Stuttgart, 1935.

Hemelrijk, Emily A.: Matrona Docta. Educated women in the Roman élite from Cornelia to Julia Domna, London u.a., 1999.

GÜNTHER, RosmaRIE: «Sexuelle Diffamierung und politische Intrigen in der Republik: P. Clodius Pulcher und Clodia», in: Späth, Thomas, WagnerHasel, Beate (Hrsg.): Frauenwelten in der Antike. Geschlechterordnung und weibliche Lebenspraxis, Stuttgart u.a., 2000, 227-241.

V. Hesberg-Tonn, Bärbel: Coniunx Carissima. Untersuchungen zum Normcharakter im Erscheinungsbild der römischen Frau, Stuttgart, 1983.

Hillard, Tom: «On the Stage, Behind the Curtain: Images of Politically Active Women in the Late Roman Republic», in: Garlick, Barbara, Dixon, Suzanne, Allen, Pauline (Hrsg): Stereotypes of Women in Power. Historical Perspectives and Revisionist Views, New York u.a., 1992, 37-64.

Huzar, Eleanor G.: «Mark Antony: Marriages vs. Careers», in: CJ, 81 (1985/86), 97-111.

Kornemann, Ernst: Römische Geschichte. Bd. 2. Kaiserzeit, Stuttgart, ${ }^{4} 1954$.

Kowalewski, Barbara: Frauengestalten im Geschichtswerk des T. Livius, München / Leipzig, 2002.

Krause, Jens-Uwe: Witwen und Waisen im Römischen Reich I: Verwitwung und Wiederverheiratung, Stuttgart, 1994. 
Krause, Jens-Uwe: Witwen und Waisen im Römischen Reich II: Wirtschaftliche und gesellschaftliche Stellung von Witwen, Stuttgart, 1994.

KRECK, BETTINA: Untersuchungen zur politischen und sozialen Rolle der Frau in der späten römischen Republik, Marburg, 1975.

Kunst, Christiane: «Eheallianzen und Ehealltag in Rom», in: WagnerHasel, Beate, Späth, Thomas (Hrsg.): Frauenwelten in der Antike. Geschlechterordnung und weibliche Lebenspraxis, Stuttgart, 2000, 32-52.

Kunst, Christiane: «Frauenzimmer in der römischen domus», in: HARICHSchwarzbauer, Henriette, Späth, Thomas (Hrsg.): Gender Studies in den Altertumswissenschaften:Räume und Geschlechter in der Antike, Trier, 2005, 111-131.

Kunst, Christiane: Livia. Macht und Intrigen am Hof des Augustus, Stuttgart, 2008.

O. A.: «Fulvia», in: Herlosssohn, Carl (Hrsg.): Damen Conversations Lexikon, Bd. 4, Adorf, 1935, 282.

Pomeroy, Sarah B.: Frauenleben im klassischen Altertum, Stuttgart, 1985.

PrESCENDI, FRANCESCA: «Weiblichkeitsideale in der römischen Welt: Lucretia und die Anfänge der Republik», in: Späth, Thomas, Wagner-Hasel, Beate: Frauenwelten in der Antike. Geschlechterordnung und weibliche Lebenspraxis, Stuttgart / Weimar, 2000, 217-227.

Russell, BrigitTe F.: «The Emasculation of Anthony: The Construction of Gender in Plutarch's Life of Antony», in: Helios, 25 (1998), 121-138.

Schubert, Charlotte: «Homo politicus - Femina privata? Fulvia: Eine Fallstudie zur späten römischen Republik», in: FeICHTINger, BARbara, WÖHrLe, Georg (Hrsg.): Gender Studies in den Altertumswissenschaften: Möglichkeiten und Grenzen, Trier, 2002, 65-79.

Virlouvet, Catherine: «Fulvia the Woman of Passion», in: Fraschetti, Augusto (Hrsg.): Roman Women, Chicago / London, 2001, 66-81.

Wallace-Hadrill, ANDREW: «Engendering the Roman House», in: KleINer, Diana, Matheson, Susan B. (Hrsg.): I Claudia. Women in Ancient Rome, Austin, 1996, 104-115.

Welch, Kathryn E.: «Antony, Fulvia and the ghost of Clodius in 47 B.C.», in: GER, 42 (1995), 182-201.

Wiseman, Timothy P.: «Pulcher Claudius», in: HSCP, 74 (1970), 207-221. 